\title{
CIENCIA JURÍDICA O TÉCNICA POLÍTICA: ¿ES POSIBLE UNA CIENCIA DEL DERECHO?
}

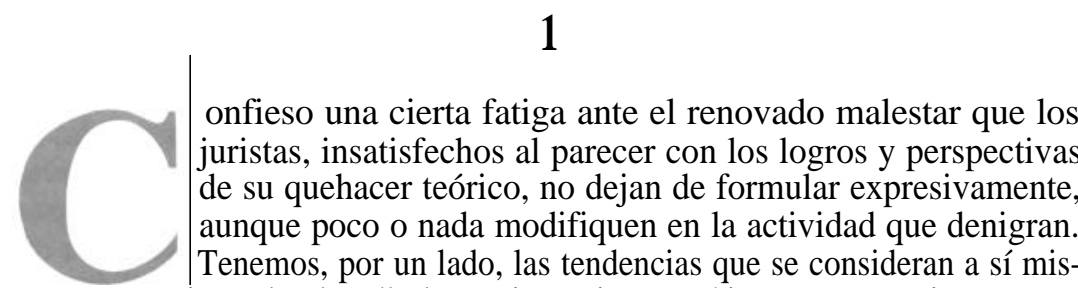
mas progresistas dando pábulo a orientaciones críticas en que se invoca una teoría revolucionaria cuyo mayor defecto, hasta la fecha, es el no haber sido elaborada. Estos críticos de la izquierda denuncian airadamente, no sólo la supuesta insuficiencia de la ciencia jurídica corriente, insuficiencia debida a una incapacidad aparente para abarcar el dominio completo de su tema objetivo de investigación, sino el incurrir quizás sin saberlo, en una oscura confabulación destinada a perpetuar el dominio de este o aquel grupo de poder, o, con mayor abstracción e imprecisión, a facilitar la reproducción de algún sistema económico y social inicuo. De donde resulta que el inocente jurista, dedicado acaso a pergeñar algunas páginas sobre la perención procesal de alguna abstrusa acción civil, o cosa pareja, se ve convertido de la noche a la mañana en cómplice necesario de una acción nefasta. Por la derecha y por el otro lado, tenemos las líneas nostálgicas de alguna escolástica medieval, como las que dicen abrevar en el tomismo o en alguna de sus múltiples variantes, que fulminan a la dogmática comúnmente practicada, por incurrir en desviaciones morales condenadas a pasar por alto, por ejemplo, los principios que, a través de chispazos o recursos metódicos similares, captaríamos en algún hábito del entendimiento o de la voluntad -fenómenos todos ellos que la psicología contemporánea ignora-, como el que oscuramente se suele denominar sindéresis. Y vemos así a devotos iusfilósofos, que, según supongo, rehuirían espantados someterse, al ir al dentista, a las técnicas de los sacamuelas del siglo XII, anatemizar la actividad de juristas del siglo XX que no respetarían las pautas que habrían respetado los inexistentes científicos sociales del Medievo.

Pero corresponde reconocer que aún los juristas «normales» (en sentido kuhniano) de nuestro tiempo, quizás con un fervor más intenso que el manifestado por los biólogos, los astrónomos, los físicos o los matemáticos, no cesan en la interesante tarea de cuestionar el status científico de lo que hacen. E inclusive el jurista sin desvelos teóricos, el jurista práctico, suele incurrir en bizantinas discusiones metodológicas que, por lo que se sabe, no alteran excesivamente el sueño de carpinteros, tipógrafos, especialistas en la aceleración de partículas elementales, o de honestos jardineros, para mencionar a otros tantos técnicos prácticos.

Pongo de lado en este escrito la referencia a aquellas posturas que reniegan enteramente de la cientificidad de la jurisprudencia, sea porque el derecho, al ser un dato histórico cambiante y contingente, no admitiría ser ob- 
jeto de una ciencia pensando cánones quizá aristotélicos, cánones que obligan, por cierto, a renegar de buena parte de las ciencias modernas, incluídas las exactas. Pongo también de lado, por ahora, el tratamiento de las tesis harto frecuentes en las tendencias autodenominadas «críticas», que atribuyen a los juristas distintos grados de ceguera, miopía o estrabismo, cuando no perversidad moral o política, al no hacerse cargo suficientemente de aquellas características del derecho que, para estos revolucionarios académicos, son de inexcusable tratamiento: la infra o la supraestructura económica o ideológica, la glosa de algún oscuro dictamen de C. Marx o Tomasso d'Aquino, o el descuido de alguna otra nota atribuida al derecho por esos autores que efectivamente la ciencia jurídica contemporánea se empeña en pasar por alto. No discuto tampoco -aunque sí lo haré más adelante frente a una interpretación que ahora cunde- la opinión que reniega de la posibilidad de alguna alcurnia teórica para la jurisprudencia, en cuanto ésta, por algún sino inescrutable, tendría que contentarse con ser un producto de la razón práctica sobre lo cual, como se sabe, algo dijeron Aristóteles y sus intérpretes escolásticos. Descarto también, y por fin, las líneas que, aún admitiendo que la jurisprudencia pueda exhibir al menos una pretensión teórica, el conocimiento producido habría sido logrado sin echar mano de ciertos procedimientos, variadamente bautizados de intuitivos, hermenéuticos, retóricos o propios de un «olfato» específicamente jurídico, que no encajan muy bien en modelos de ciencia más discretos, que no repudian de los recursos lógicos ni de otros procedimientos tradicionales.

\section{2}

Por cierto que esta penosa situación ha provocado una abundante literatura destinada a diagnosticar, desentrañar y remediar la afligente situación de la jurisprudencia. También esta situación ha acuciado a pensadores importantes de nuestra época, empezando por Kelsen, a una permanente y renovada atención por el problema del status epistemológico de la ciencia del derecho. Bobbio, por ejemplo, a lo largo de extensa preocupación por el saber jurídico, ha tenido muchas ocasiones de ocuparse de este insólito aspecto de la actividad científica en torno al derecho. Así, en distintos momentos, destacó el cariz técnico de la labor teórica de los juristas; en otro, la relación estrecha que la jurisprudencia mantiene con el análisis del lenguaje y la lógica; al tratarse, según se dice, de un conocimiento normativo tuvo que examinar los posibles sentidos de tal atribución, pues no es nada claro que sea una ciencia normativa; por fin, al prestar atención a los usos del conocimiento jurídico, hizo hincapié en las diversas funciones que el conocimiento científico del derecho puede adoptar en sistemas sociales de diverso grado de desarrollo. Podría aludir aquí a recientísimos trabajos de Aarnio, Pattaro o Jori; pero me interesa examinar las tesis recientemente formuladas por Manuel Atienza en su «Introducción al derecho» de 1985, no sólo por tratarse de un pensador actual en el mejor sentido de la palabra sino porque me parece preocupante que una visión semejante sea vista como la adecuada para inculcar a los estudiantes que recién se lanzan a los vericuetos de la denostada ciencia dogmática del derecho. 
Cabe subrayar, por de pronto, que Atienza, como es corriente, se ve constreñido a considerar el modelo dogmático de ciencia jurídica como el paradigma vigente en estos tiempos. Su severo cuestionamiento de la situación presente del conocimiento jurídico -la pregunta es, ni más ni menos: ¿es la jurisprudencia un saber científico físico? (op. cit. p. 274/283)- parte de ciertas consideraciones que no cabe sino reconocer como válidas: 1) no existe una ciencia única en relación con el derecho, sino que contamos con una pluralidad de saberes con status epistemológico variados: ciencia dogmática, teoría general del derecho, sociología jurídica, lógica normativa, etc. El cuestionario crítico atañe principalmente a la dogmática tradicional y cabe preguntarse cómo se relaciona con esas otras disciplinas, cuyo rango científico es menos discutido o discutible. 2) El discurso de la dogmática jurídica tiene, enojosamente, un alcance normativo, un sentido práctico, que afectará menos a otras disciplinas más puramente teóricas. El jurista, por de pronto, normalmente figura entre los destinatarios de las mismas normas que estudia y, en principio, las aceptaría como «criterio exclusivo de regulación» de la conducta social, y, por ende, de la propia. «La elaboración dogmática» provocaría así «una aproximación entre el sujeto y el objeto de la investigación mucho mayor de lo que ocurre en el caso de las otras disciplinas sociales». Y ¿cómo no pensar que ello introduzca un factor de distorsión del objeto?

Dadas estas desgraciadas características, resultaría que la «determinación del objeto de estudio, el derecho vigente, no parece que pueda hacerse con independencia del análisis de la eficacia sociológica de las normas», que modelan también la conducta del jurista. «Todas las operaciones normativas -decreta Atienza- son, de alguna forma, políticas». El jurista, sujeto a esa operación, está políticamente condicionado y, en consecuencia, las normas que pretende describir o interpretar sólo podrían serlo partiendo de la aceptación de los fines políticos que las mismas están destinadas a lograr. De ahí que, en la realidad de la práctica jurisprudencial, las funciones cumplidas por la dogmática no se agotan en la ascéptica construcción de un sistema conceptual, sino en la elaboración de «criterios para la aplicación de las normas vigentes» y de «criterios para el cambio del derecho». Vale decir: hacer ciencia jurídica es hacer política, pues «el jurista teórico ha cumplido siempre una función prescriptiva»: «contribuye a formar el derecho». No debe sorprender, pues, que la dogmática recibida, pretendida disciplina teórica, dedicada a clasificar y ordenar, y quizás explicar, un cierto material normativo de ciertos actos empíricos de creación de derecho sólo sea «una disciplina normativa», tanto en cuanto a su objeto, como a su método y a su función. Atienza remacha el clavo: la ciencia o ciencias jurídicas padecerían de una incurable incapacidad, que hace sospechosas todas sus formulaciones. No podrían distinguir rigurosamente entre su objeto -las normas jurídicas- y su propio discurso, las proposiciones referentes a esas normas. ¿Cómo dudar de que el lenguaje de la ciencia jurídica no sea tan prescriptivo como las normas que dice estudiar y cómo diferenciar el discurso pragmático del político del discurso del jurista que, a la postre, dice lo mismo?

Además, pretender que esta cuestionada ciencia, o este confuso haz de saberes de dudosa cientificidad, logre la mentada neutralidad valorativa que, desde Weber, es piedra de toque (creen muchos) de toda ciencia social digna 
de tal norma, es utópico. El saber jurídico, para Atienza, constituye «una actividad valorativa», no sólo en cuanto aporta criterios para la modificación del derecho y para su aplicación, sino en cuanto la elaboración misma de su aparato conceptual le exige hacerse cargo de los valores ínsitos en las normas. De ahí a renegar de la posible neutralidad teórica del jurista frente a su objeto no hay gran trecho. El jurista es un político que, como ciertos anormales, n'ose pas dire son nom. Bien merece, pues, los denuestos que le propina la izquierda descontenta y la derecha cómplice.

En su análisis, retorna Atienza el examen del conocido alegato sobre el valor científico de la jurisprudencia que pergeñara Kirchmann, un alegato, pienso, que sería bueno archivar de una buena vez, puesto que responde a una idea de ciencia que ni siquiera refleja modelo aceptable de ciencia moderna. Atienza apunta que el carácter mutable del objeto jurídico su contingencia y la manifiesta inutilidad y falta de actualidad de la actividad del jurista científico, que Kirchmann denuncia, son características que pueden hacerse extensivas a la jurisprudencia pensada como una mera técnica social.

La cuestión queda planteada así: la pretensión científica de la jurisprudencia provendría de «la falta de prestigio social de los juristas y de la labor teórica que desarrollan», carencia que se pretende superar usufructuando el rótulo de «científico». El reproche es conocido: en nada difiere del que hoy se dirige habitualmente contra el psicoanálisis y recuerda al que desde el siglo XVI, se espeta contra la astrología u otros desvaríos. Por un lado nuestro autor sostiene que la dogmática jurídica no es una ciencia «porque su objetivo no es el de conocer por conocer, sino el de conocer para actuar», sonsonete en el que pervive la idea de una ciencia platonizante pensada como pura contemplación gratuita, y la de una razón práctica productora de una teoría que no limita a su practicante a la mera contemplación, sino que lo hace actuar, esto es: una razón que no se limita a declamar la verdad de ciertas legalidades, sino que performativamente las realiza. Se trata claro de esa razón práctica y de su correspondiente scientia o tejné que los neoescolásticos añoran y los neopositivistas repudian. Pero hay más en las afirmaciones de Atienza: la falta de percepción, por Kirchmann y otros epistemólogos contemporáneos, de una «distinción adecuada» entre ciencia y técnica, hace desdeñar la verdad de la tesis que Atienza formula en términos quizás (o, mejor sin quizás) exagerados: «La jurisprudencia es una técnica y no puede dejar de serlo». El fundamento de esta terminante afirmación nos es ahorrado. Con todo, no implicaría relegar a los juristas a un lugar social incómodo, donde se verían acompañados por plomeros, sacamuelas y remendones. La jurisprudencia, en tanto que técnica, exhibiría sí los achaques que Kirchmann atribuye a la atribulada ciencia jurídica, pero esos achaques no son tan desdorosos de tratarse de una mera técnica; más, constituirían elementos esenciales de tal técnica. Esta segunda tesis quedaría atenuada con los siguientes argumentos, con los que Atienza cierra el correspondiente capítulo de su libro y, según parece, deja formulada su opinión personal: «carece de sentido y de interés plantearse el problema de si la jurisprudencia es o debe llegar a ser una ciencia...»; sí importaría la «cuestión 
pertinente... de saber si, en cuanto técnica (la jurisprudencia) puede incorporar y utilizar conocimiento científico y conocimiento tecnológico procedentes, en principio, de otras áreas (por ejemplo, conocimiento proveniente de la lógica formal, la economía, la sociología, la teoría de juegos y de decisión, de la informática, etcétera)». Entiendo que estas afirmaciones expresan tesis más que discutibles. Discutámolas.

\section{4}

Si se deseara distinguir a la jurisprudencia, en tanto ciencia, de la jurisprudencia en tanto técnica, y si de esa distinción dependiera el poder pensar con alguna claridad qué sea eso que hacen los juristas y qué cosa sea lo que producen, pareciera importante saber a qué atenerse con respecto a qué se entienda por ciencia y qué, por técnica. Pero lo cierto es que no lo sabemos y que Atienza tampoco arroja mayores luces al respecto. No se trata de una distinción evidente ni comprensible de suyo.

Lo que parece es que, en la discusión glosada, quedaran tácitos ciertos presupuestos que fundan las tesis expresas de Atienza. Pero no hay razón alguna para aceptar como verdades indiscutibles tales presupuestos. No aludiré a la nebulosa distinción entre un conocimiento teórico (un conocer por conocer, frase hecha que no sé qué sentido tenga) y un conocimiento práctico (un conocimiento resultante de las actividades de una razón práctica cuya mera existencia es sospechosa). En cambio, sí me referiré a la tesis fundante según la cual ciencia (teoría) y técnica (práctica) son dominios excluyentes, tanto vistas como actividades, como vistas como un discurso. Por el contrario, pareciera que lo típico de las ciencias modernas y de las técnicas respetables es el no dar pie a tal dicotomía. En nuestro tiempo y desde Galileo, según cuentan, ciencias y técnicas están inextricablemente enlazadas: las ciencias modernas no sólo dan lugar a técnicas; aun en las ciencias formales, donde un teorema puede traducirse en un algoritmo y éste ser usado en un cálculo, sino que esas técnicas son la aplicación de las leyes teóricas. Las técnicas desarrolladas son, expresamente, técnicas científicas. La distinción entre ciencias y técnicas, si cabe, se da según los contextos de uso del discurso científico: se usa la teoría para alcanzar ciertos efectos empíricos, pero también se recurre a ciertas prácticas para verificar, corregir, refutar o extender la teoría. De ahí que sea un lugar común de la metodología contemporánea destacar el carácter científico de las técnicas vigentes, para diferenciarlas de otro tipo de técnicas, como las primitivas utilizadas en las prácticas religiosas, en las artes y artesanías o, inclusive en la vida cotidiana. Hasta un escritor tan poco perspicaz como Ortega no pudo dejar de apuntar esta notoria característica de las ciencias y las técnicas modernas. De ahí que interrogarse sobre si una cierta actividad o un cierto discurso sea ciencia o técnica, implica sustentar una disyunción que el pensamiento actual más bien conjuga. Si la jurisprudencia que hoy practicamos fuera necesariamente una técnica, en el sentido indicado, seguramente habría que suponerla fundada en conocimientos teóricos a los que no habría razón, de existir, para negarles el título de ciencia. Y, en principio, pareciera que la técnica de los juristas, en cuanto pueden realizar ciertos actos y predecir ciertos efectos a la luz de la aplicación de ciertas leyes, difiere bastante de las técnicas del 
brujo de la tribu, del pontífice romano o de los sacerdotes de algún culto. No se ve por qué el fundador teórico de las afirmaciones y actividades técnicas del jurista sólo pudieran relacionarse con las ciencias en la medida en que recurrieran a ese pot-pourri (lógica, sociología, economía, teoría de juegos, etc.. .) que invoca Atienza. Los juristas del presente y los de ayer sean técnicos científicos o chamanes iluminados, no trabajan de ese modo ecléctico: lo que el jurista dice y hace, en su práctica profesional se funda en enunciados técnicos sustentados en un conocimiento teórico del sistema normativo de que se trate, y no en el recurso a aquellas variadas disciplinas

Es que, en el texto que gloso, aparece, creo, una cierta ambigüedad sobre qué entender por técnica. Puesto que si bien una técnica es un repertorio de actividades orientadas a lograr ciertos fines (una modificación en el estado de cosas), también la técnica es aquel conjunto de enunciados legales cuya aplicación o realización pretende alcanzarse con esas actividades. Tenemos tanto la actividad del técnico que manipula los ingredientes y mecanismos de un procedimiento industrial, como las reglas técnicas, fundadas en enunciados teóricos, que orientan a este técnico en lo que hace. En cuanto nos ocupamos de la jurisprudencia, en cambio, la actividad realizadora (aplicación de normas, interpretaciones de leyes, promulgación de códigos etc. ), esto es, las actividades que producen derecho, son vistas redondamente como una actividad política, en ese sentido amplio, es considerada una técnica (social) científica, en el sentido en que lo son corrientemente las prácticas clínicas del médico o la intervención en un proceso industrial del ingeniero. Pensamos que el jurista profesional (al que la opinión corriente no considera un político en el sentido en que lo es un parlamentario), es capaz de llevar a cabo actividades fundadas en su conocimiento previo de ciertos enunciados normativos, manteniendo inclusive un suficiente nivel de neutralidad valorativa tanto con respecto de los valores que esas normas presupongan como con respecto del valor que quepa atribuir al efecto producido. Esto es, el postulado «sometimiento» a los valores del ordenamiento a que el jurista estaría condenado, o aun su compromiso personal con los mismos, no impiden que pueda formular hipótesis sobre cursos de acción normados, susceptibles de verificación, falsificación, sistematización, etc. En este respecto no me parece acertada la propuesta de Atienza de reducir la dogmática a una técnica no científica, técnica que quizás podría alcanzar un cierto nivel de cientificidad recurriendo a los conocimientos de otras disciplinas que tienen al parecer y para nuestro autor, rango de ciencia.

Si este análisis es correcto, no se advierte cuál sea la razón que haya o qué suerte de fatalidad toque en suerte a la jurisprudencia, para tener que asentir a la excesivamente fuerte tesis de Atienza, aquella de que «la jurisprudencia es una técnica y no pueda dejar de serlo». Creo, más bien, que habría que limitarse a comprobar que los juristas cumplen actividades de distinto tipo, algunas de las cuales no hay inconveniente en caracterizar como científicas y en denominar «ciencia» a su formulación, así como no veo inconveniente en pensar como acciones técnicas a múltiples actividades y expresiones de los juristas. Algunas de esas técnicas tienen hoy nivel científico, según los rasgos generales que a las ciencias se atribuyen actualmente. Cierto que no responde esta ciencia jurídica a los tipos corrientes en las ciencias empíricas o a las ciencias formales. Pero ello no basta para descalificar- 
la como ciencia. También es cierto que muchas de las técnicas utilizadas por los juristas no tienen el carácter de una técnica científica, manteniéndose el nivel de prácticas más primitivas. Pero si haciendo una generalización imprudente, todas las actividades de los juristas, y su discurso, son considerados acciones políticas -incurriendo en gran confusión de lenguaje y, también, introduciendo subrepticiamente una motivación persuasiva-, parece notorio que habría que aceptar que las actividades de los juristas y la ciencia jurídica dogmática no son, ya no ciencias teóricas conforme al modelo de las ciencias duras (puesto que, desgraciadamente, no hay tal tipo de conocimiento teórico en el terreno de la política), sino tampoco técnicas en el sentido indicado de técnicas respaldadas en un conocimiento teórico objetivo. ¿Se parece más el jurista al político en trance de tomar una decisión a la luz de cierta valoración o de cierta ideología, o semeja más al psicólogo en su práctica clínica? ¿O cabe compararlo con científicos como el sociólogo o el historiador, terrenos teóricos indispuestos pero donde la actividad experimental o la práctica clínica son inexistentes? La respuesta es obvia: algunas de las cosas que hace el jurista lo asemejan al político; otras, lo acercan al ingeniero, al médico, al psicólogo. ¿Por qué poner todo bajo un único rasero?

5. Se me ocurre que habría que indagar, con un detalle y rigor imposible en estas páginas, qué haya detrás de ese continuo interrogarse, crónico en los juristas, por el status teórico de su discurso y por el sentido objetivo de sus actividades. Se me ocurre que en las tendencias contemporáneas que machaconamente ponen en el banquillo de los acusados, a una ciencia jurídica que, por otra parte, los propios impugnadores utilizan y desarrollan, se oculta una veta de irracionalismo, inspirada quizás en los tantos irracionalismos políticos, ideológicos, religiosos, etc., que hoy prosperan. 